\title{
Medical student selection: a tentative attempt to establish a code of practice
}

\author{
JOHN ANDERSON，DAVID HUGHES， RICHARD WAKEFORD
}

\section{Summary and conclusions}

Each year medical schools in the United Kingdom select about 3800 entrants from about 12000 applicants. The problem of selection is thus substantial, but the objectives, policies, and practices of different medical schools differ sharply and details of the procedures used are rarely made clear. There is no reliable or up-to-date information available for schools, careers advisers, and prospective candidates to keep abreast of these practices and policies and of changes made to them.

A code of practice for medical student selection might be helpful and would not only facilitate discussion about the appropriateness and fairness of the widely differing practices but make it easier to evaluate the procedures used. Such a code should list the academic and personal requirements for the school, state any quotas for types of entrants, and describe the selection procedures.

\section{Introduction}

The problem of selecting medical students for undergraduate medical courses is substantial. For entry into United Kingdom medical schools in October 1978 there were 12089 applicants, of whom 3785 were accepted. ${ }^{1}$ Applicants are allowed five choices of medical school on the application form; there were therefore likely to have been some 60000 applications for under 4000 places. A typical medical school ${ }^{2}$ seeking just under 130 entrants therefore received applications from almost 2000 would-be students.

Medical School, University of Newcastle upon Tyne, Newcastle 1 JOHN ANDERSON, MB, FRCP, academic subdean

DAVID HUGHES, BA, LIOB, senior administrative assistant

Cambridge University School of Clinical Medicine

RICHARD WAKEFORD, BA, senior research associate
A selection process is therefore inevitable, and the General Medical Council's (GMC) Survey of Basic Medical Education indicated that there are striking differences among the selection objectives, policies, and practices of British medical schools. ${ }^{3}$ (These select students quite independently, with only the mechanics of the application process being organised centrally by the Universities' Central Council on Admissions (UCCA).) Some schools, for instance, see themselves as principally local or regional ones and favour local applicants; others place the highest emphasis on A-level grades; yet others rely on the interview as a principal method of selection provided a basic minimum academic standard is met. Details of the selection procedures are, however, rarely made entirely clear, ${ }^{45}$ and there is no simple way for anyone concerned about selection to ascertain the particular mechanism used by any individual school.

\section{Published guidance}

None of the medical schools' prospectuses detail selection policy or procedure in more than the most general terms, while the Careers Research and Advisory Centre Degree Course Guide-Medicine ${ }^{6}$ and the Secondary Heads Association booklet Entrance Requirements for Medical School ${ }^{7}$ contain superficial, sparse, sometimes outdated, and often misleading references to selection procedures. The Secondary Heads Association booklet is particularly culpable: vital information is often given simply in the form of a yes/no answer to a standard question-for example, Q: "Is motivation tested ?" A: "Yes." Referring to Newcastle, this booklet states that "Three advanced level subjects are preferred" (three are in fact mandatory for second-year entry from sixth-form to all UK medical schools) and that "subjects other than science are welcome." This is a misleading oversimplification of the true requirements*-no mention is made of the A-level subjects that are acceptable-and is of little help to sixth-form candidates.

Thurman's booklet $A$ doctor ... or else ?8 and his report on medical schools' practices regarding graduate applicants' are a little more

*Three A levels: chemistry or physical science must be one while the other two can be in any approved subjects except human biology; $O$ level passes in physics, mathematics, and a biological subject must be offered if these subjects are not offered at A level. 
useful, but omit important information and will rapidly become out of date. We were therefore alarmed to discover that the Secondary Heads Association booklet is widely used by teachers and careers advisers. ${ }^{5}$ At a recent GMC conference on the selection of medical students ${ }^{10}$ no fewer than four speakers asked for more information to be available to prospective applicants about selection methods, as well as about medical schools and career opportunities in medicine.

\section{Fairness and effectiveness}

Concern about the fairness of medical school selection procedures (how explicit and open they are, whether applicants know all the "rules," whether there are hidden criteria) is also often expressed in the lay press. A recent disturbing example, taken at face value, was a report by Toynbee ${ }^{11}$ describing what occurred in some selection interviews. The effectiveness of selection procedures (Is the type of student sought in fact selected ?) has been criticised less often, possibly because effectiveness has not been distinguished from fairness. Jacobson ${ }^{12}$ recently argued that without clear and explicit objectives selection procedures cannot be effective. She also queried how appropriate the systems were in the first place: were they looking for the "right" sort of students ? McManus and Lockwood" have argued that conventional medical school entry requirements "unnecessarily restrict the range of abilities to be found among medical students," and Parkhouse ${ }^{13}$ claimed that the present system "leads us to pay too little attention to screening out people who might make bad doctors."

\section{Research evidence}

What is surprising is the lack of research in the UK on selection for entry to medical school and the lack of knowledge about the success (or otherwise) of selection procedures. One recent study ${ }^{14}$ in Ireland examined the relationship between performance at the school-leaving examination and performance in medical school examinations, but only limited data (correlation coefficients) were presented, and the implications for selectors were unclear. Another study ${ }^{15}$ found that one selection panel (out of three) at Nottingham Medical School admitted students who performed appreciably worse in the course than those admitted by the other two, but no explanation was offered.

The most recent study ${ }^{16}$ found that selection for Glasgow Medical School has not been biased by the sex, class, or medical parenthood of entrants and that the Scottish Sixth Year Studies examinations are a reliable predictor of student performance. Nevertheless, these are only preliminary results from a continuing study, and, as the authors admitted, the Glasgow school is not only less bound by the UCCA system than most others but also takes most of its entrants from its own (albeit large) region. Few details are given about the entry requirements and selection procedures (although about $24 \%$ of candidates are interviewed).

The pointers that one can obtain from international research into selection for medical school give cause for concern. For instance, although the use of high A-level grades as a condition of entry may be a convenient filter, studies in the United States have shown that purportedly "low aptitude" students can perform better in medical school than their peers who score higher on examinations before entry. Parkhouse ${ }^{13}$ has said: "Practically all of us except the most highly talented and flagrantly hypocritical would have to agree that obtaining very high A-level grades is not a prerequisite for becoming a good doctor, or even a successful professor."

The use of interviews in selection is even more dubious as an indicator of success in the medical course and is unproved as a technique in the longer-term quest for "good doctors." For example, Gough" ${ }^{17}$ reviewed one experiment and concluded: "Interviewers quite clearly favoured applicants who were more attractive as human beings, even though these qualities were not related themselves to subsequent performance in medical training." Yet at the GMC conference, one dean said that at the interview the school had to "rely on the experience of its selectors who know what qualities to look for and how to find evidence of motivation in a brief space of time." ${ }^{\prime \prime}$ But what are these qualities, and is the time-consuming search for them worth while?

\section{A tentative code of practice}

In the absence of published criteria for selection the system is hard if not impossible to evaluate. If medical schools could establish precisely what they are attempting in their selection policies they could then evaluate the success of their policies. Schools may find it difficult to establish precisely the aims of their selection procedures; indeed, there may be several parallel objectives in any school, and admissions procedures are likely to differ from school to school. Nevertheless, it should be a relatively straightforward task to make explicit the selection arrangements adopted by any particular institution. A code of practice to which all medical schools might subscribe could therefore be considered as a first step-a tentative code appears in the Appendix.

The code covers: entry requirements, desirable (and undesirable) attributes of applicants, and the selection process. Publication of and adherence to such guidelines would be of value to all concerned with medical school selection. Selection practices at individual schools may change from year to year, so any code that might eventually be agreed would need to be revised annually, to include changes in any individual institution and to avoid disharmony between published and actual practice-one of the main failings of the existing booklets. Again, not all institutions concerned with medical student selection might be able to subscribe to all parts of the code-the arrangements at Oxford and Cambridge, for instance, where selection is principally in the hands of many individual colleges, would be difficult to document precisely.

The question of quotas or targets for various groups of entrants is a delicate topic, and statements about foreign or overseas students need to be factually accurate and carefully phrased, just as actual practice needs to prevent any ambiguous or "racial" interpretation. Similar considerations apply to statements on target figures for mature and graduate applications, students from medical families, and children of alumni.

\section{Conclusions}

Within universities it is often claimed that "medicine is different," and our proposals may be interpreted as yet another assertion of the unique status of medical schools. Yet these proposals, while presented for consideration by medical schools, may be capable of adaptation and use by selectors in all faculties. It is certainly true that most medical applicants are interested in the one course and not, as is often the case with other aspiring undergraduates, in a variety of courses. To that extent there is a specialised approach among medical applicants.

Some may also feel that fair and accurate statements on selection cannot be provided. Nevertheless, the proposal for establishing an agreed code of practice is worthy of discussion. If and when instituted, those concerned with admissions within medical schools could begin to appraise the philosophy of their admissions practice and policy. The code would be a first step towards permitting research into the effectiveness of selection systems, it would permit more informed judgment about their fairness, and it would facilitate informed discussion about their appropriateness. It would also permit evaluation of experiments in selection, such as taking into account factors other than traditional criteria or adopting a more positive policy towards the admission of mature students, both of which were recommended by the Royal Commission on the National Health Service. ${ }^{18}$

The methods of the Glasgow study ${ }^{16}$ might serve as a basis for further work. Nevertheless, this type of study can be extended only if the basic data are available for analysis. As a minimum, some of the fog of ignorance and mystique that so often cloaks medical school admissions should be dispersed, to the benefit of medical school admissions officers, those giving advice to prospective students, and-most important of all-the applicants.

\section{Appendix}

OUTLINE OF A TENTATIVE CODE OF PRACTICE

(A) Schools are asked to state clearly with respect to school-leaver applicants to the normal medical course: (a) matriculation and course requirements for entry; and $(b)$ any preferred subject mix or mixes. If a premedical year is offered, similar information should be given with regard to this.

(1) What are the matriculation requirements?

(2) What are the subject requirements for the medical course-for example, $A$ and $O$ levels; Scottish $O$ and $H$ grades; Irish schoolleaving qualifications? 
(3) What are the normal grades required (a) for premedical or first-year entry (where applicable), (b) for preclinical or second-year entry?

(4) Under what (if any) circumstances may an applicant enter with lower than "normal" requirements ?

(5) Is any note taken of the timing of an applicant's school-leaving examinations ? (For example, are grades received at a second attempt regarded differently ?)

(6) Are any particular combinations of entry qualifications regarded as particularly desirable or undesirable? If so, what are they ?

(B) Schools should state what general non-academic attributes and/or personal backgrounds are sought and/or deprecated in their student entry. Which of the following are considered significant ? Please comment where appropriate:

(1) Background-for example, school, family.

(2) Home location in relation to the medical school.

(3) Physical and cultural attainments.

(4) Interests.

(5) Health

(6) Experience gained before medical school.

(7) Age.

(8) Any other factors.

(C) Schools are asked to state whether or not there are any quotas or targets for particular groups of entrants. If not, schools are asked to comment on the typical composition of their intake in the following terms :

(1) Male/female.

(2) Mature and graduate students.

(3) Local students.

(4) Students from medical families.

(5) Offspring and siblings of alumni.

(6) Scottish/English/Northern Irish/Welsh students.

(7) Foreign students.

(D) Schools are asked to provide as full a description as possible of their selection practices. The following points are intended as a framework only; additional comment is welcome.

(1) Is selection under the control of an individual, a group of staff or a committee ? Please describe.

(2) What, if any, attention is paid to the order of preference given to the medical school by the student ? Are any students excluded on the basis of the preference given ? If an applicant does not give medicine for all of his choices, what effect does this have on the school's attitude towards him? How does the school treat "bracketed" preferences or preferences made in alphabetical order?

(3) What proportion of applicants is interviewed ?

(4) If interviews are used, are they: (a) to identify unacceptable candidates ? If so, what attributes are regarded as unacceptable ? (b) to identify desirable entrants ? If so, what attributes are regarded as desirable? $(c)$ for what other purpose ?

(5) How long is a typical interview, and by whom is it conducted ?

(6) Is evidence of motivation looked for ? If so, how ?

(7) 'To what extent is note taken of headmasters' or tutors' reports, and under what circumstances?
(8) The nature of any condition regularly attached to offers of places should be made clear.

(9) Additional comments.

(E) Any different entry requirements, selection policies or procedures applying to special groups of applicants-for example, those mentioned in (C) - should be stated. In particular, requirements and arrangements for abbreviated courses (including direct entry to clinical schools) should be made clear where these are provided for graduate or other mature applicants.

(F) Some universities offer, in addition to the medical course, degree courses in subjects such as medical biology which are sometimes taken by students who fail to gain acceptance for medicine. Accurate evidence as to the prospects for such graduates being accepted for subsequent clinical training should be made available.

(G) Schools are asked to provide information on the possibility of visits by potential applicants to the individual institutions. Can such visits be made before final choices need to be submitted to the UCCA ?

\section{References}

${ }^{1}$ Universities Central Council on Admissions. Sixteenth Report, 1977-8. Cheltenham: UCCA, 1979.

${ }^{2}$ General Medical Council. Basic medical education in the British Isles. London: Nuffield Provincial Hospitals Trust, 1977:21.

3 General Medical Council. Basic medical education in the British Isles. London: Nuffield Provincial Hospitals Trust, 1977:29-33.

4 McManus IC, Lockwood DNJ. Medical-school admissions policies. Lancet $1979 ; \mathrm{i}: 106$.

- Connolly RC. Medical-school admissions policies. Lancet 1979 ;i :272.

- Rubery ED, ed. Degree course guide 1978-9: medicine. Cambridge: Careers Research and Advisory Centre, 1978.

7 Secondary Heads Association. Entrance requirements for medical school. London: Secondary Heads Association, 1978.

${ }^{8}$ Thurman JC. A doctor ... or else? Norwich: Yare Valley Publishers, 1979.

- Thurman JC. Some notes on the admission of graduate applicants to the Medical Schools. Med Educ 1979;13:4-9.

${ }^{10}$ Conference on the Selection of Medical Students. Report. London: General Medical Council, 1979.

11 Toynbee P. Guardian 1978 Dec 18:13.

12 Jacobson B. Personal view. Br Med $\mathcal{F}$ 1978;ii: 1638

13 Parkhouse J. The control of medical education. Fournal of the Royal Society of Medicine $1979 ; 72: 453-9$.

${ }^{14}$ Irwin WG, Bamber JH. Characteristics of senior medical students at Belfast. Med Educ 1978;12:117-23.

${ }^{15}$ Mitchell JRA. The role of the interview in student selection. $S$ Afr Med $\mathcal{F}$ 1978;54:932-3.

${ }^{16}$ Lennox B, Dick I, Graham B. Comparison of admission criteria and medical school progress: preliminary results from a simple computer system. Med Educ 1979;13:374-9.

17 Gough HG. How to: Select medical students. Medical Teacher 1979;1: 17-20.

${ }^{18}$ Royal Commission on the National Health Service. Report. London: HMSO, 1979:278 (Cmnd 7615).

(Accepted 8 February 1980)
Dried fruit such as sultanas and prunes contain mineral oil. Is this oil carcinogenic?

The use of mineral oil in food manufacture and as a food additive in the UK is subject to Government regulation (Statutory Instrument 1966 No 1073). In 1975 the Food Additives and Contaminants Committee (FACC) reviewed the regulations and made several recommendations. ${ }^{1}$ Among these was a recommendation that the use of mineral oil as an additive to prunes, sultanas, currants, and raisins should continue to be permitted but only up to a reduced level of $0.25 \%$ by weight (previously $0.5 \%$ ). Its use in these dried fruits was deemed necessary to maintain the "free-flowing" properties of the fruit, to deter insect infestation, to help moisture retention, to retard aging, and to improve appearance. Carcinogenic polycyclic aromatic hydrocarbons (PAHs) are present in crude mineral oils. During the manufacture of food-grade mineral oils particular attention is paid to reducing the concentrations of PAHs so far as is technologically possible. In their 1975 review the FACC recommended that in future all mineral hydrocarbons used in food should comply with a stringent test, such as the four-wavelength ultraviolet absorption test of Howard et $a l^{2}$ to ensure that oils have been adequately processed to remove PAHs. They also recommended that in new regulations, specifications for liquid mineral hydrocarbons for use in food should be based on the 1973 British Pharmacopoeia monograph rather than on the 1963 one. The 1975 FACC recommendations have not yet been translated into new regulations, but this is only a matter of time.

Although the regulations currently in force are less stringent than those proposed, it is most unlikely that any hazard to health from the extremely low concentrations of PAHs could theoretically remain undetected by the current statutory analytical methods, which are by no means lax. Boyd and Doll ${ }^{3}$ found a higher incidence of history of use of medicinal paraffin among patients with gastrointestinal cancers than among controls. For various reasons, however, they did not consider that this observation implied that cancers were caused by the paraffin.

1 Food Additives and Contaminants Committee. Report No 20. London: HMSO,

1975 .
Howard JW, Haenni EO, Joe FL. An ultraviolet criterion for total polynuclear romatic hydrocarbon content of petroleum waxes in food additive use. Fournal of the Association of Official Agricultural Chemists $1965 ; 48: 304-15$.

- Boyd JT, Doll R. Gastrointestinal cancer and the use of liquid paraffin. $B r f$ Cancer $1954 ; 8: 231-7$. 